\title{
Administration of amifostine in the stage of remission induction can benefit the patients with hematological malignancy in autologous stem cell transplantation: a retrospective study
}

\author{
Min Wu ${ }^{1 \#}$, Kefei Wu ${ }^{2 \#}$, Pingping Chen ${ }^{1}$, Pei $\mathrm{Li}^{3}$, Yanhui Xie ${ }^{1}$ \\ ${ }^{1}$ Department of Hematology, Huadong Hospital, Fudan University, Shanghai, China; ${ }^{2}$ Department of Hematology and Oncology, Shanghai \\ Children's Medical Center, Shanghai Jiao Tong University, Shanghai, China; ${ }^{3}$ Department of Hematology, Huashan Hospital, Fudan University, \\ Shanghai, China \\ Contributions: (I) Conception and design: M Wu; (II) Administrative support: K Wu; (III) Provision of study materials or patients: M Wu, Y Xie; (IV) \\ Collection and assembly of data: K Wu, Y Xie; (V) Data analysis and interpretation: Y Xie; (VI) Manuscript writing: All authors; (VII) Final approval \\ of manuscript: All authors. \\ "These authors contributed equally to this work. \\ Correspondence to: Yanhui Xie. Department of Hematology, Huadong Hospital, Fudan University, No. 221 West Yan'an Road, Shanghai 200040, \\ China. Email: yanhuixie@yandex.com.
}

\begin{abstract}
Background: To investigate whether the administration of amifostine in the stage of remission induction can benefit patients with hematological malignancy in autologous stem cell transplantation (ASCT).

Methods: Two historical groups of patients who received prophylactic amifostine in the stage of remission induction and ASCT (group A, n=95) or amifostine in ASCT only (group B, n=73) were included. The chemotherapy-associated side effects in peripheral blood stem cell (PBSC) mobilization, total average monocyte per kilogram in stem cells collections, hematologic toxicity and engraftment kinetics, nonhematologic toxicity, therapeutic response after ASCT were compared between the two groups.

Results: For PBSCs mobilization, the rate of fever in group A was significantly higher (24/95 vs. 2/73; $\mathrm{P}=0.0001)$, but the incidence of emesis was significantly lower (8/95 vs. 27/73; $\mathrm{P}=0.0001)$ compared with group B. For collected PBSCs, the average total mononuclear cells per kilogram in group A were $7.031 \times 10^{8} / \mathrm{kg}$, while it was $4.624 \times 10^{8} / \mathrm{kg}$ in group $\mathrm{B}(\mathrm{P}=0.0001)$. The median duration of neutropenia was 8.62 days in group A, which was significantly shorter than that of group B by almost 2 days (10.51 days, $\mathrm{P}=0.038)$. The incidence of oral mucositis was $8.4 \%$ in group $\mathrm{A}$ and $32 \%$ in group $\mathrm{B}(\mathrm{P}=0.0002)$. No significant differences of therapeutic response were observed between the two groups.
\end{abstract}

Conclusions: Prophylactic amifostine can reduce mucositis, improve monocytes collection and promote hematopoietic recovery in ASCT.

Keywords: Amifostine; remission induction; hematological malignancy; autologous stem cell transplantation (ASCT)

Submitted Mar 06, 2020. Accepted for publication Jul 17, 2020.

doi: $10.21037 /$ tcr-20-1366

View this article at: http://dx.doi.org/10.21037/tcr-20-1366

\section{Introduction}

High-dose therapy supported by autologous stem cell transplantation (ASCT) has been established as a consolidation or salvage therapy in patients with hematological malignancies such as multiple myeloma (MM), lymphoma, leukemia and so on (1-5). Despite the possibility for a cure, the low selectivity of chemotherapeutic agents with high doses can cause chemotherapy-related side-effects, such as mucositis, hemorrhagic cystitis, and infections. Some side-effects limit the intensity of dose administration, affect the patients' quality of life with increased cost, and are even life-threatening. Therefore, to 
maintain the dose intensity while protecting patients from treatment-induced side effects, the cytoprotection of nonmalignant cells would be needed.

Amifostine is a widely used cytoprotective agent and has been initially developed as a radioprotective agent. Amifostine is a prodrug, which can be rapidly converted to an active thiole (WR-1065) by alkaline phosphatase located in cell membranes, to protect normal cells from the cytotoxic effects of alkylating, platinum-based chemotherapy, radiotherapy and so on. Amifostine exhibits a selective protective effect on normal cells (6-8), as the expression of alkaline phosphatase is lower in malignant tumor cells. Previous study has found the cytoprotective effect of amifostine during therapy for hematological malignancy. Hartmann et al. (9) found that amifostine could decrease hepatic and renal functional lesions and mucositis through accelerating hematopoietic recovery and shortening the length of hospital stay during ASCT. Other studies have suggested that the application of amifostine can help patients tolerate a higher dose of melphalan, which improves response rates with the potential to improve clinical outcomes $(10,11)$.

However, though many data address the protective effects of amifostine in ASCT, no study has evaluated whether regular application of amifostine during remission induction could result in long-term benefits in ASCT. Therefore, in this study, we conducted a retrospective analysis, comparing treatment-associated side-effects and the reconstitution of blood cells in patients auto-transplanted with peripheral blood progenitor cells (PBPCs) between two groups, which were arranged by the use of amifostine in the stage of remission induction or not. We present the following article in accordance with the STROBE reporting checklist (http:// dx.doi.org/10.21037/tcr-20-1366).

\section{Methods}

\section{Patients' characteristics}

All of the patients were affected by hematological malignancy, including Hodgkin's lymphoma (HL), nonHodgkin's lymphoma (NHL), multiple myeloma (MM) and leukemia (AML or ALL) between July 1995 and December 2017 in the hematology departments of Huashan Hospital and Huadong Hospital, which is affiliated with Fudan University were included. Criteria for inclusion were required as follows: ECOG performance status of 0 or 1 , adequate bone marrow function (WBC-count $\geq 4,000 / \mu \mathrm{L}$, platelet-count $\geq 100,000 / \mu \mathrm{L}$ and granulocyte count $\geq 2,000 / \mu \mathrm{L}$ ), adequate renal (serum creatinine concentration $\leq 1.2 \mathrm{mg} / \mathrm{dL}$ and creatinine clearance $\geq 80 \mathrm{~mL} / \mathrm{min}$ ) and liver function (bilirubin level $\leq 2.0 \mathrm{mg} / \mathrm{dL}$, and AST and ALT $\leq 3$ times normal). Parameters for ineligibility included presence of brain metastases, symptoms of ischaemic heart disease, and history of congestive heart failure or myocardial infarction within immediate preceding 6 months and/or clinically significant arrhythmia. The patients were divided into two groups, the patients in group A received ASCT with prophylactic amifostine in the stage of remission induction and ASCT, while group B received amifostine in ASCT only. The study was conducted in accordance with the Declaration of Helsinki (as revised in 2013). The study was approved by the ethical committee of East China Hospital of Fudan University (NO.: 2017K050) and informed consent was taken from all the patients.

\section{Amifostine administration}

The scheduled adult dose of amifostine (Merro, Dalian, China) is $400 \mathrm{mg} / \mathrm{m}^{2}$ in the stage of remission induction and $750 \mathrm{mg} / \mathrm{m}^{2}$ in ASCT, administered as a 30-min infusion approximately $15 \mathrm{~min}$ before chemotherapy and $30 \mathrm{~min}$ after the infusion of antiemetic. The scheduled amifostine for each patient was diluted into $100 \mathrm{~mL}$ sterile $0.9 \%$ sodium chloride solution. Amifostine was administered after patients were adequately hydrated. During the infusion of amifostine, baseline blood pressure was controlled and rechecked every $5 \mathrm{~min}$, and the infusion would be disrupted if a $20 \%$ decrease of systolic blood pressure was observed. Hypotension was treated by hydration with an i.v. infusion of normal saline and placing the patient in the Trendelenburg position. For all of the patients with hypotension, the infusion of amifostine could be restarted within $5 \mathrm{~min}$ after the baseline blood pressure returned to normal. To reduce the appearance of symptomatic hypotension, the patient should be placed in a horizontal position when being administered with amifostine, and $500-1,000 \mathrm{~mL}$ of normal saline could be infused before amifostine if necessary.

\section{Evaluation of transplant-related toxicity}

Hematological toxicity and side-effects were assessed in the stage of peripheral blood stem cell (PBSC) mobilization and conditioning in ASCT, by evaluating reconstitution in terms of days to achieve a polymorphonuclear cell count of 
$500 \times 10^{9} / \mathrm{L}$ and a platelet count of $20,000 \times 10^{9} / \mathrm{L}$.

Before transplantation, liver, renal and cardiac functions were evaluated in all patients. These functions were also monitored at regular intervals during ASCT. Fever, rash, emesis, oral mucositis, infection, hemorrhage, hemorrhagic cystitis, occlusive hepatic veins syndrome (OHVS) and leukoencephalopathy were assessed during ASCT, and monocyte counts were measured in mobilization.

\section{Patient care}

Central venous catheters (CVCs) were placed in all patients before conditioning. After a mobilization of etoposide $15 \mathrm{mg} /$ $\mathrm{kg}$ for two days and CTX $30 \mathrm{mg} / \mathrm{kg}$ for one day, leukocyte counts were monitored at regular intervals. Granulocyte colony-stimulating factor (G-CSF) was given for six days (d-6 to d-1) after the reconstitution of peripheral leukocytes began. On d-2 and -1, PBSCs were collected and counted by flow cytometry. If mononuclear cells counts were lower than basic requirement, a third day of collection would be performed. Cyclophosphamide $60 \mathrm{mg} / \mathrm{kg}$, mitoxantrone $60 \mathrm{mg} / \mathrm{m}^{2}$ and etoposide $30 \mathrm{mg} / \mathrm{kg}$ were given to patients as the conditioning regimen when the stem cell collection was completed. On day +1 , PBSCs were infused back into the patient's blood after the chemotherapy treatment ended on $\mathrm{d} 0$.

All patients received $5 \mu \mathrm{g} / \mathrm{kg} / \mathrm{d}$ G-CSF immediately after PBSCs infusion until the white blood cell (WBC) count reached $5.0 \times 10^{9} / \mathrm{L}, 50 \mu \mathrm{g} / \mathrm{kg} / \mathrm{d}$ interleukin- 11 and $300 \mathrm{U} / \mathrm{kg} / \mathrm{d}$ recombinant human thrombopoietin were administered until the platelet count reached $20,000 \times 10^{9} / \mathrm{L}$. Blood component transfusion was used to maintain hemoglobin and platelet levels above $7 \mathrm{~g} / \mathrm{dL}$ and $10 \times 10^{9} / \mathrm{L}$, respectively. For mouth care, antimicrobial prophylaxis and febrile episode treatments were performed, as previously described (12). Briefly, mouthwash was performed everyday. If the body temperature was $38.3{ }^{\circ} \mathrm{C}$, blood cultures were taken from peripheral blood and CVC and repeated after $1 \mathrm{~h}$ and alternate days for as long as fever and/or bacteremia persisted. Empirical parenteral antibiotic therapy was started and continued for 5 days until resolution of clinical and microbiological findings. The empirical antibiotic regimen included a third-generation cephalosporin plus an aminoglycoside or carbapenem; a glycopeptide was added at the discretion of the attending physician. Antibiotic regimens were modified according to microbiological results. If fever persisted empirical amphotericin $\mathrm{B}$ (AMFB) was added 7 days after the beginning of antibiotic therapy.

\section{Response criteria and statistical analysis}

Pre- and post-transplant physical condition was evaluated according to ECOG criteria. Residual disease was assessed by computerized tomography (CT) scan, bone marrow biopsy and magnetic resonance imaging (MRI).

\section{Statistical analysis}

Data were analyzed by descriptive statistical methods. The mean values for continuous variables were compared using the two-tailed student's $t$-test. The Chi-square test was used for nominal data. The analysis in this study was performed by using STATA (version 12, Stata Corp., College Station, TX, USA).

\section{Results}

\section{Basic characteristics}

There were total 95 patients in group A with average age of 44 years old, while there were 73 patients in group B with average age of 33 years old. Other characteristics including diagnosis, disease status, prior ASCT status and prior number of cycles were also recorded and compared. Both study groups were well balanced in respect to patients and tumor characteristics (Table 1).

\section{Chemotherapy-associated side effects in PBSCs mobilization}

In the stage of mobilization, we unexpectedly observed a higher rate of fever in group A than that in group B (24/95 vs. 2/73; $\mathrm{P}=0.0001)$. In addition, the incidence of emesis, which was taken as a main described short-term side effect of amifostine, was significantly lower in group A than that in group $\mathrm{B}(8 / 95$ vs. $27 / 73 ; \mathrm{P}=0.0001)$. Furthermore, the lowest count of WBCs in group A was significantly higher than that of group B (1.154 vs. 1.233; $\mathrm{P}=0.0443)$. However, we failed to observe significant differences between the two groups in the incidence of rash, infection, hemorrhage, hepar, renal and cardiac function, as well as in the recovery time of the platelets and neutrophils (Table 2).

\section{Stem cells collections}

All patients in both groups proceeded with stem cell collection. A remarkable difference in the ability to collect stem cells was observed between the two groups (Figure 1). 
Table 1 Patients' characteristics

\begin{tabular}{|c|c|c|}
\hline Variables & Group A & Group B \\
\hline Gender (M/F) & $65 / 30$ & $46 / 27$ \\
\hline Age [range] & $44[16-67]$ & 33 [12-69] \\
\hline \multicolumn{3}{|l|}{ Diagnosis } \\
\hline $\mathrm{NHL}$ & 69 & 52 \\
\hline $\mathrm{HL}$ & 8 & 6 \\
\hline MM & 11 & 10 \\
\hline AML & 3 & 3 \\
\hline ALL & 4 & 2 \\
\hline \multicolumn{3}{|l|}{ Disease status } \\
\hline Primary & 61 & 42 \\
\hline First relapse & 17 & 13 \\
\hline 2nd relapse & 2 & 0 \\
\hline Refractory & 15 & 18 \\
\hline \multicolumn{3}{|l|}{ Prior ASCT status } \\
\hline $\mathrm{CR}$ & 49 & 42 \\
\hline PR & 31 & 13 \\
\hline SD & 2 & 13 \\
\hline PD & 13 & 5 \\
\hline Prior number of cycles & 7 [2-19] & 7 [1 25] \\
\hline
\end{tabular}

NHL, non-Hodgkin's lymphoma; HL, Hodgkin's lymphoma; MM, multiple myeloma; AML, acute myeloid leukemia; ALL, acute lymphoblastic leukemia; CR, complete response; $P R$, partial response; SD, stable disease; $\mathrm{PD}$, progressive disease.

The total average monocyte per kilogram was $7.031 \times 10^{8} / \mathrm{kg}$ in the group A (range, $1.682 \times 10^{8} / \mathrm{kg}$ to $22.817 \times 10^{8} / \mathrm{kg}$ ) and $4.624 \times 10^{8} / \mathrm{kg}$ in group B (range, $1.360 \times 10^{8} / \mathrm{kg}$ to $9.800 \times$ $\left.10^{8} / \mathrm{kg}\right)(\mathrm{P}=0.0001)$.

\section{Hematologic toxicity and engraftment kinetics}

The lowest count of WBCs for both groups was $0.21 \times 10^{9} / \mathrm{L}$ and $0.13 \times 10^{9} / \mathrm{L}$, while there were no significant differences between the two groups $(\mathrm{P}=0.1112)$. Although there were also no significant differences of the time to recover neutrophil count $>0.5 \times 10^{9} / \mathrm{L}$ between the two groups $(13.43$ vs. $\left.14.13 ; \mathrm{P}=0.310^{8}\right)$, the median duration of neutropenia (ANC $<0.5 \times 10^{9} / \mathrm{L}$ ) was 8.62 days in group A, which was almost two days significantly longer than that of group $\mathrm{B}$ (10.51 days) $(\mathrm{P}=0.038)$. In contrast, amifostine did not affect platelet reduction or recovery (Table 3).

\section{Non-bematologic toxicity}

The occurrence of oral mucositis was significantly lower in group A compared with that in group B (8/95 vs. 23/73; $\mathrm{P}=0.0002)$ as we expected. Furthermore, only 2 patients among the 95 patients had episodes of rash in group A, in contrast, there were 8 cases among the 73 patients in group $\mathrm{B}(\mathrm{P}=0.045)$. However, we did not observe any significant differences of the occurrence of emesis, infection, hemorrhage, liver or renal dysfunction, cardiac toxicity and so on, between the two groups (Table 4).

\section{Therapeutic response after ASCT}

In group A, 83 of 95 patients achieved CR (87.4\%), which is higher than that before ASCT (49/95, 51.6\%). Compared with group B, 62 patients achieved CR after ASCT (84.9\%) and showed a raised CR rate $(42 / 73,57.5 \%)$. However, we failed to show any significant differences of the therapeutic response or ASCT-associated death between the two groups (Table 5).

\section{Discussion}

This retrospective study compared the treatment with or without amifostine as a cytoprotective agent in the stage of remission induction of patients with hematological malignancy in ASCT, suggesting that early and regular use of amifostine in chemotherapy could further benefit the patients in ASCT.

Tolerance to amifostine was acceptable. It has been reported that the main side effects of amifostine are shortterm hypotension, hypocalcemia, emesis, nausea and flulike symptoms (12). In this study, we did not observe any severe side effects associated with the administration of amifostine. We even found a lower rate of emesis among the patients who received amifostine regularly. However, it was unexpected to observe a higher rate of fever in the amifostine group. But it was not parallel to the strikes of infection, thus, we believed that it was caused by a record bias.

The administration of amifostine during the stage of remission induction could further protect stem cells in ASCT in this study. The average total monocytes per kilogram collected was higher in amifostine group than that in control group. The role of the chemoprotectant property 
Table 2 Chemotherapy-associated side effects, neutrophil and platelet recovery in PBSC mobilization

\begin{tabular}{|c|c|c|c|}
\hline Variables & Group A & Group B & $P$ value \\
\hline Rash & 2 & 6 & 0.142 \\
\hline Emesis & 8 & 27 & ${ }^{*} 0.0001$ \\
\hline Infection & 18 & 12 & 0.842 \\
\hline Liver dysfunction & 2 & 3 & 0.655 \\
\hline Renal dysfunction & 0 & 1 & 0.438 \\
\hline The lowest count of white blood cells & 1.514 & 1.233 & *0.0443 \\
\hline Time to reach the lowest white blood cells & 11.745 & 11.986 & 0.6073 \\
\hline The lowest count of platelets & 79.79 & 78.93 & 0.9075 \\
\hline Time to reach the lowest platelets & 12.3 & 12.1 & 0.6825 \\
\hline
\end{tabular}

${ }^{*}$, statistically significant. PBSC, peripheral blood stem cell.

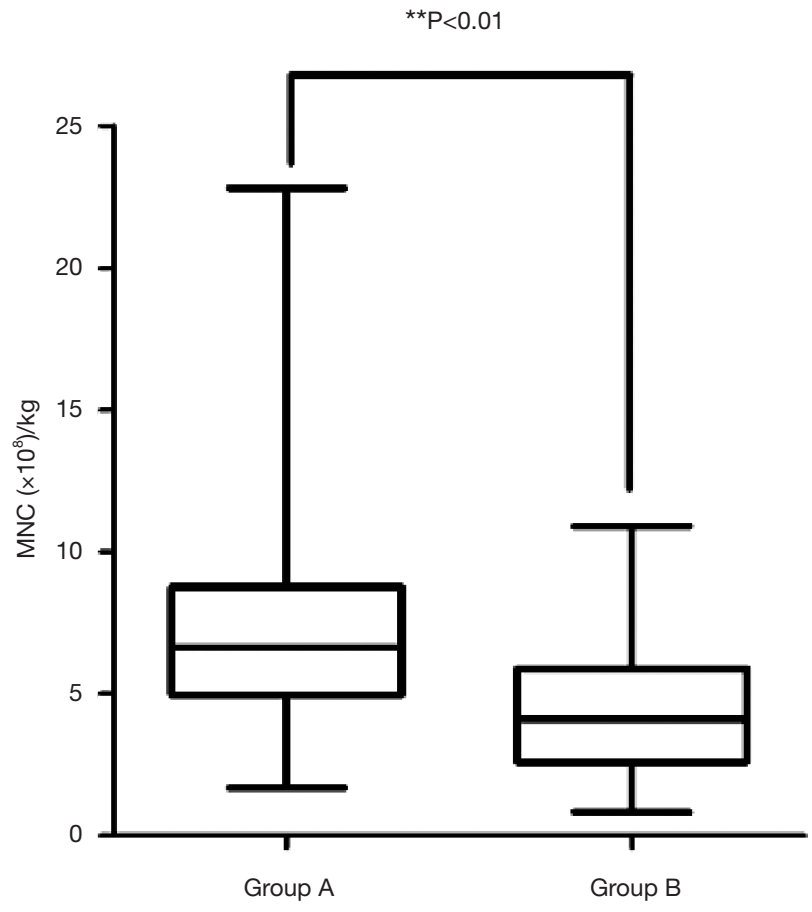

Figure 1 Mobilization results were expressed as the total average monocyte per kilogram collected. There was a significant difference of the average mononuclear cell collection between the two groups $(\mathrm{P}=0.0001)$. of amifostine rested on the lower hematologic toxicity and better engraftment kinetics. During the hematopoietic recovery, we observed a shorter duration of neutropenia in amifostine group, meaning a lower incidence of infection and suggesting the benefits of amifostine pretreatment to the hematologic system. Such beneficial effects for normal hematopoietic cells found in our study has also been found in several previous researches. In a large randomized control trial consisting of 242 patients with advanced ovarian cancer, pretreatment with amifostine before each cycle of chemotherapy of cyclophosphamide and cisplatin resulted in a reduced incidence of grade 4 neutropenia (44\% vs. $65 \%$ ) and transfusions (13). Emmanouilides et al. (14) found that in patients receiving ASCT after salvage chemotherapy involving 2 to 4 cycles of DHAP, a pretreatment of amifostine could facilitate stem cell collection, with a larger number of CD34+ stem cell collected.

The comparison between the two groups, with regards to the non-hematologic toxicity, suggested that amifostine had a protective effect on mucosal tissue. This outcome is further confirmed by the significant reduction in the incidence of oral mucositis, which is also in accordance with previous study $(14,15)$. Unlike previous trials, we did not observe amifostine-related rash in current study $(16,17)$. On the contrary, the incidence of rash in amifostine group 
Table 3 Neutrophil and platelet recovery after conditioning

\begin{tabular}{|c|c|c|c|}
\hline Variables & Group A & Group B & $P$ value \\
\hline Time to recover neutrophil count $>0.5 \times 10^{9}$ & 13.43 & 14.13 & 0.3108 \\
\hline Duration of neutropenia & 8.62 & 10.51 & *0.038 \\
\hline The lowest count of platelets & 12.68 & 13.5 & 0.8503 \\
\hline Duration of platelet $<20 \times 10^{9}$ & 6.9 & 6.1 & 0.5718 \\
\hline Time to recover platelet count $>20 \times 10^{9}$ & 13.477 & 14.288 & 0.4749 \\
\hline
\end{tabular}

${ }^{*}$, statistically significant.

Table 4 Chemotherapy-associated side effects after conditioning

\begin{tabular}{lccc}
\hline Variables & Group A & Group B & P value \\
\hline Rash & 2 & 8 & ${ }^{*} 0.045$ \\
Emesis & 44 & 52 & 0.098 \\
Infection & 78 & 60 & 1 \\
Hemorrhage & 13 & 9 & 1 \\
Liver dysfunction & 7 & 11 & 0.213 \\
Renal dysfunction & 2 & 4 & 0.408 \\
Cardiac toxicity & 7 & 9 & 0.431 \\
Hemorrhagic cystitis & 1 & 5 & 0.091 \\
Oral mucositis & 8 & 23 & ${ }^{*} 0.002$ \\
HPVO & 0 & 1 & 0.438 \\
Leukodystrophy & 0 & 0 & 1 \\
Died & 2 & 3 & 0.655 \\
\hline
\end{tabular}

*, statistically significant. HPVO, hepatic portal vein occlusion.

was even lower than that in the control group Amifostine is reported to selectively protect normal rather than tumor tissue against cytotoxic damage induced by some anticancer agents and radiation therapy, owing to its physiological differences in drug activation, alkaline phosphatase concentration and $\mathrm{pH}$ between normal and tumor tissue (18). In this study, as disease status, prior ASCT status and prior number of cycles showed no difference between the two groups, we have further confirmed that amifostine do not affect the anti-tumor effect of chemotherapy for the non-significant difference of CR rate between the two groups.

There were also some limitations in this study. The
Table 5 Post-transplant statues (4 weeks after transplant)

\begin{tabular}{lccc}
\hline Variables & Group A & Group B & P value \\
\hline CR & 83 & 62 & 0.909 \\
PR & 7 & 2 & 0.305 \\
PD & 3 & 6 & 0.191 \\
Died & 2 & 3 & 0.655 \\
\hline CR, complete response; CR, complete response; PD, progressive \\
disease.
\end{tabular}

dosage of amifostine applied in this study was not optimal. During the stage of remission induction, the dose of amifostine was $400 \mathrm{mg} / \mathrm{m}^{2}$, which was different from the recommended tolerated dose of amifostine at $750 \mathrm{mg} / \mathrm{m}^{2}$ applied in ASCT (19). However, higher dose of amifostine would result in severe emesis and withdrawal. In view of the benefits that we observed in this study, we took $400 \mathrm{mg} / \mathrm{m}^{2}$ of amifostine as an effective and tolerated dose for patients preparing for ASCT. This study failed to record the exact grade of mucositis and emesis and the number of CD34+ stem cells among the collected monocytes. A future randomized study is still needed to confirm these preliminary results.

In conclusion, severe mucositis may affect eating, which has a bad impact on the nutrition state of patients. Mucositis and long periods of neutropenia may increase the incidence of severe infection, which could further cause transplantation-related death. The administration of amifostine during the stage of remission induction could benefit patients in future ASCT, with lower incidences of oral mucositis, a shorter duration of neutropenia, a more rapid engraftment of neutrophil and a larger number of stem cells collected. 


\section{Acknowledgments}

Funding: None.

\section{Footnote}

Reporting Checklist: The authors have completed the STROBE reporting checklist. Available at http://dx.doi. org/10.21037/tcr-20-1366

Data Sharing Statement: Available at http://dx.doi. org/10.21037/tcr-20-1366

Conflicts of Interest: All authors have completed the ICMJE uniform disclosure form (available at http://dx.doi. org/10.21037/tcr-20-1366). The authors have no conflicts of interest to declare.

Ethical Statement: The authors are accountable for all aspects of the work in ensuring that questions related to the accuracy or integrity of any part of the work are appropriately investigated and resolved. The study was conducted in accordance with the Declaration of Helsinki (as revised in 2013). The study was approved by the ethical committee of East China Hospital of Fudan University. (NO.: 2017K050) and informed consent was taken from all the patients.

Open Access Statement: This is an Open Access article distributed in accordance with the Creative Commons Attribution-NonCommercial-NoDerivs 4.0 International License (CC BY-NC-ND 4.0), which permits the noncommercial replication and distribution of the article with the strict proviso that no changes or edits are made and the original work is properly cited (including links to both the formal publication through the relevant DOI and the license). See: https://creativecommons.org/licenses/by-nc-nd/4.0/.

\section{References}

1. Ansell SM. Hodgkin Lymphoma: Diagnosis and Treatment. Mayo Clin Proc 2015;90:1574-83.

2. Barlogie B, Jagannath S, Desikan KR, et al. Total therapy with tandem transplants for newly diagnosed multiple myeloma. Blood 1999;93:55-65.

3. Henig I, Zuckerman T. Hematopoietic stem cell transplantation-50 years of evolution and future perspectives. Rambam Maimonides Med J 2014;5:e0028.
4. Philip T, Guglielmi C, Hagenbeek A, et al. Autologous bone marrow transplantation as compared with salvage chemotherapy in relapses of chemotherapy-sensitive nonHodgkin's lymphoma. N Engl J Med 1995;333:1540-5.

5. Singh AK, McGuirk JP. Allogeneic Stem Cell Transplantation: A Historical and Scientific Overview. Cancer Res 2016;76:6445-51.

6. Hartmann JT, Knop S, Fels LM, et al. The use of reduced doses of amifostine to ameliorate nephrotoxicity of cisplatin/ifosfamide-based chemotherapy in patients with solid tumors. Anticancer Drugs 2000;11:1-6.

7. Afzal SM, Ainsworth EJ. Radioprotection of mouse colony forming units-spleen against heavy-charged particle damage by WR 2721. Radiat Res 1987;109:118-26.

8. Treskes M, Nijtmans LG, Fichtinger-Schepman AM, et al. Effects of the modulating agent WR2721 and its main metabolites on the formation and stability of cisplatinDNA adducts in vitro in comparison to the effects of thiosulphate and diethyldithiocarbamate. Biochem Pharmacol 1992;43:1013-9.

9. Hartmann JT, von Vangerow A, Fels LM, et al. A randomized trial of amifostine in patients with highdose VIC chemotherapy plus autologous blood stem cell transplantation. Br J Cancer 2001:84:313-20.

10. Thieblemont C, Dumontet C, Saad H, et al. Amifostine reduces mucosal damage after high-dose melphalan conditioning and autologous peripheral blood progenitor cell transplantation for patients with multiple myeloma. Bone Marrow Transplant 2002;30:769-75.

11. Bensinger WI, Becker PS, Gooley TA, et al. A randomized study of melphalan $200 \mathrm{mg} / \mathrm{m}(2)$ vs $280 \mathrm{mg} / \mathrm{m}(2)$ as a preparative regimen for patients with multiple myeloma undergoing auto-SCT. Bone Marrow Transplant 2016;51:67-71.

12. Offidani M, Corvatta L, Olivieri A, et al. Infectious complications after autologous peripheral blood progenitor cell transplantation followed by G-CSF. Bone Marrow Transplant 1999;24:1079-87.

13. Kemp G, Rose P, Lurain J, et al. Amifostine pretreatment for protection against cyclophosphamide-induced and cisplatin-induced toxicities: results of a randomized control trial in patients with advanced ovarian cancer. J Clin Oncol 1996;14:2101-12.

14. Emmanouilides C, Territo M, Andrey J, et al. A randomized phase II study of amifostine used as stem cell protectant in non-hodgkin lymphoma patients receiving cisplatin-based salvage chemotherapy prior to stem cell transplant. J Hematother Stem Cell Res 2001;10:887-93. 
15. Capelli D, Santini G, De Souza C, et al. Amifostine can reduce mucosal damage after high-dose melphalan conditioning for peripheral blood progenitor cellautotransplant: a retrospective study. Br J Haematol 2000;110:300-7.

16. Bardet E, Martin L, Calais G, et al. Subcutaneous compared with intravenous administration of amifostine in patients with head and neck cancer receiving radiotherapy: final results of the GORTEC2000-02 phase III randomized trial. J Clin Oncol 2011;29:127-33.

17. Koukourakis MI, Pitsiava D, Giatromanolaki A, et

Cite this article as: $\mathrm{Wu} \mathrm{M}, \mathrm{Wu} \mathrm{K}$, Chen $\mathrm{P}, \mathrm{Li} \mathrm{P}, \mathrm{Xie} \mathrm{Y}$. Administration of amifostine in the stage of remission induction can benefit the patients with hematological malignancy in autologous stem cell transplantation: a retrospective study. Transl Cancer Res 2020;9(9):5147-5154. doi: $10.21037 /$ tcr-20-1366 al. Amifostine-related fever-rash during fractionated radiotherapy: diagnostic and predictive role of C-reactive protein. Am J Clin Oncol 2011;34:281-5.

18. Yuhas JM. Active versus passive absorption kinetics as the basis for selective protection of normal tissues by S-2-(3aminopropylamino)-ethylphosphorothioic acid. Cancer Res 1980;40:1519-24.

19. Jantunen E, Kuittinen T, Nousiainen T. A pilot study on feasibility and efficacy of amifostine preceding high-dose melphalan with autologous stem cell support in myeloma patients. Leuk Lymphoma 2002;43:1961-5. 